\title{
Prognosis of tumor infiltrating lymphocytes in operable tongue cancer patients
}

\author{
Wan-Yu Chen ${ }^{1 *}$, Yih-Leong Chang ${ }^{2}$, Sung-Hsin Kuo ${ }^{1}$, Ann-Lii Cheng ${ }^{3}$ \\ From Society for Immunotherapy of Cancer 29th Annual Meeting \\ National Harbor, MD, USA. 6-9 November 2014
}

\section{Background}

The immune microenvironment is important to the pathophysiology of head and neck squamous cell carcinoma (HNSCC). Our aim was to investigate the prognostic significance of tumour-infiltrating lymphocytes (TILs) in operable tongue cancer patients treated with curative surgery and adjuvant radiotherapy with or without chemotherapy.

\section{Patients and methods}

The presence of CD3+, CD4+, CD8+ and FOXP3+ TILs in tumor tissues obtained from 93 patients during surgery were examined by immunohistochemistry. Correlation between clinicopathological features and TILs was investigated. The prognostic roles of TILs for local recurrencefree survival (LRFS), regional recurrence-free survival (RRFS), distant metastasis-free survival (DMFS) and overall survival (OS) were analyzed.

\section{Results}

Median follow up time was 31.4 months (range, 0.299.8 months). Higher number of CD4+ cells ( $p=0.006$ ), higher CD4/FOXP3 ratio $(\mathrm{p}=0.012)$, lower CD3/CD4 ratio $(\mathrm{p}=0.043)$, and higher $\mathrm{CD} 4 / \mathrm{CD} 8$ ratio $(\mathrm{p}=0.006)$ were correlated with the absence of lymphovascularinvasion (LVI). Patients with lower FOXP3+ TILs and higher CD8/FOXP3 ratio had marginally better RRFS ( $p=0.071$, and $\mathrm{p}=0.069$, respectively) (Figure 1 and Figure 2.). Patients with higher CD4/CD3 ratio had a significantly better DMFS ( $\mathrm{p}=0.036$ ) (Figure 3).

\section{Conclusion}

CD4+ TILs and its ratio to other TILs were inversely correlated with LVI. Higher CD4/CD3 ratio predicts

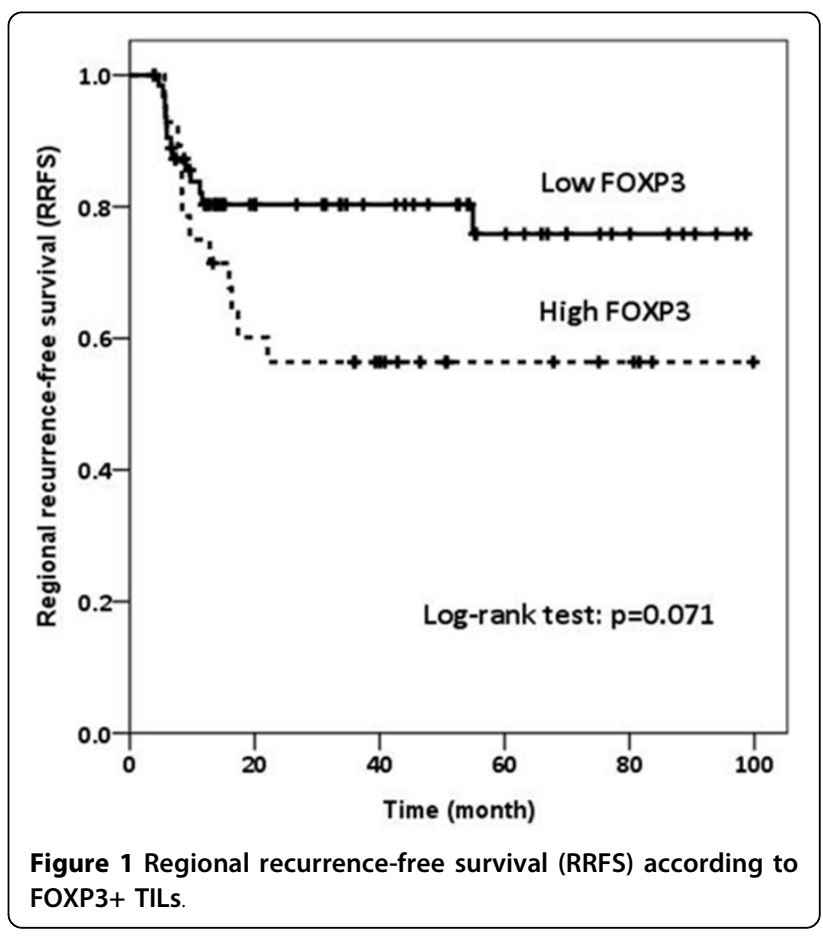

better DMFS. Prognostic role of FOXP3 in RRFS was marginally significant and warrants further investigation.

\section{Authors' details}

${ }^{1}$ Division of Radiation Oncology, Department of Oncology, National Taiwan University Hospital, Taipei, Taiwan. ${ }^{2}$ Department of Pathology, National Taiwan University Hospital and National Taiwan University College of Medicine, Taipei, Taiwan. ${ }^{3}$ Department of Oncology, National Taiwan University Hospital, Taipei, Taiwan. 

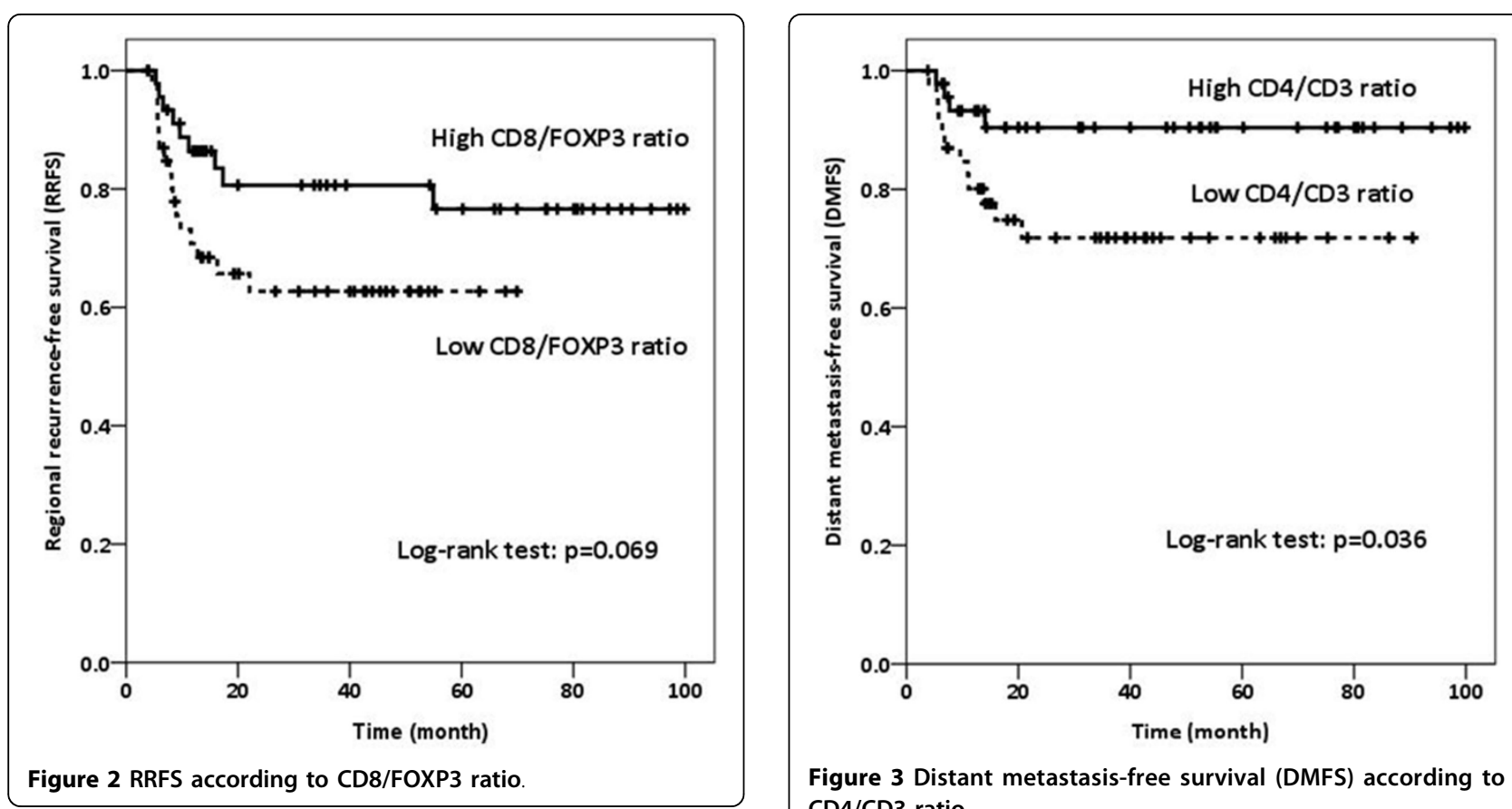

Figure 3 Distant metastasis-free survival (DMFS) according to CD4/CD3 ratio.

Published: 6 November 2014

- Convenient online submission

- Thorough peer review

- No space constraints or color figure charges

- Immediate publication on acceptance

- Inclusion in PubMed, CAS, Scopus and Google Scholar

- Research which is freely available for redistribution 